\title{
Treatment of Brain Metastases Using the Current Predictive Models: Is the Problem Solved?
}

ISSN: 2637-773X

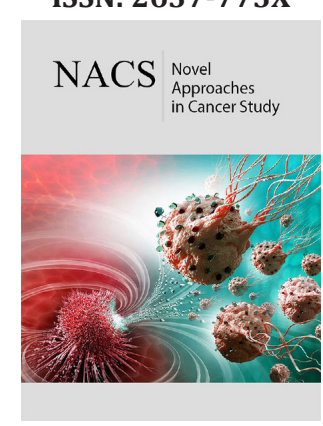

*Corresponding author: Esam Abdelaal, Department of Radiation Oncology, UPMC Hilman Cancer Centre, Waterford, Ireland, TN 38163, USA

Submission: 侮 March 05, 2020

Published: : March 20, 2020

Volume 4 - Issue 3

How to cite this article: Esam Abdelaal, Katie Delahunty. Treatment of Brain Metastases Using the Current Predictive Models: Is the Problem Solved?. Nov Appro in Can Study.4(3). NACS.000586.2020. DOI: 10.31031/NACS.2020.04.000586

Copyright@ Esam Abdelaal.This article is distributed under the terms of the Creative Commons Attribution 4.0 International License, which permits unrestricted use and redistribution provided that the original author and source are credited.

\author{
Esam Abdelaal* and Katie Delahunty \\ Department of Radiation Oncology, Ireland
}

\section{Opinion}

Brain metastases from solid tumours are the most common intracranial tumours [1] and it occur in $40 \%$ of patients with cancer [2]. The most common primary tumours that metastasize to the brain are lung(40\%),breast (25\%) and melanoma (20\%) [3]. The incidence is expected to be on the increase, due to improved survival, with use of modern cytotoxic drugs, targeted therapy, immunotherapy and modern radiotherapy techniques, in addition to greater use of magnetic resonance imaging of the brain. Brain metastases are common in the elderly, defined as above 60 years [4], and the interval between diagnosis of the primary and the development of brain metastases is variable, however some reported an average of 19 months [5] and adenocarcinoma is the commonest histology that metastasizes to the brain [6].

Many patients have multiple metastases [7] at diagnosis, although about $20 \%$ and $9 \%$ have one or two lesions respectively [8]. About half of brain metastases are asymptomatic [9], however two thirds of patients develop symptoms at the time of initial diagnosis or during the course of the disease [10], and the commonest presentations are headache, neurological deficits and seizures [11]. Staging of lung cancer includes whole body FDG PET-CT scan [12] and brain MRI as recommended by National Comprehensive Cancer Network [13]. MRI is more sensitive than contrast enhanced CT scan in detecting brain metastases and in one study about one third of patients with apparently solitary metastases based on CT scan, turned out to have multiple lesions on MRI [14].

Treatment of brain metastasis includes, best supportive care, steroids, whole brain radiotherapy, surgery and stereotactic radiotherapy or a combination of these, depending on the number, size and location of the metastases. Generally speaking, survival is poor, and is less than 2 months for patients treated with steroids only. However, whole brain radiotherapy could extend the survival up to 7 months [15]. Surgery and WBRT improved the survival up to 13.5 months in one study [16]. The average survival after stereotactic radiosurgery is 8.5 to 12.1 months $[17,18]$.

Researchers have investigated some prognostic and predictive factors for the survival of patients with brain metastases. Lagerwaard \& Levendag [19] found performance status, age, extracranial metastases and the status of the primary to be the most important factors. Hazuka et al. [20] found that initial presentation with neurologic deficit, multiple metastases to be poor prognostic factors, while solitary lesion, gross total resection and adenocarcinoma subtype improved the survival and at the same time the survival was independent of primary tumour site, presence of active extracranial disease and radiation dose.

Researchers have sought to derive scoring systems or predictive models for better selection of patients with brain metastases who would benefit from treatment and to avoid overtreating those with very poor survival. In 1997 The Radiation Therapy Oncology Group (RTOG) developed the Recursive Partitioning Analysis (RPA) [21], the Grading Prognostic Assessment (GPA) was developed in 2008 [22] and, more recently, disease specific GPAs were developed mainly for lung and breast [23]. RTOG RPA classified patients into 3 classes; Class One, those who have Karnofsky performance score (KPS) of $\geq 70$, age $<65$, and controlled primary tumour without extracranial metastases, Class 3 patients have KPS $<70$, all other 
patients fall into Class 2, including those with KPS $\geq 70$ but other unfavorable characteristics, such as uncontrolled primary tumour, extracranial metastases, or age $\geq 65$. The median survival for classes 1,2 and 3 were 7.1,4.2 and 2.3 months respectively [21,24,25]. GPA classification excluded the status of extracranial disease acknowledging only its presence or absence, it kept age and KPS and added number of brain metastases and each factor was given values of $0,0.5$ and 1. Four prognostic groups were created and the median survival was 2.6 months,3.8 months, 6.9 months and 11 months for GPA scores of 0-1,1.5-2.5,4 and 3.5-4 respectively [26].

Diagnosis-specific graded prognostic assessment was developed after the primary tumour site was shown to be an important prognostic factor in some studies [23]. Despite the availability of diverse scoring systems, there still is a lack of consensus regarding which clinical factors have the major impact in treatment decisionmaking concerning the use of WBRT. Although those predictive models are very useful for patient selection, yet making a clinical decision based on them is still a challenge as it is difficult to identify patients with very short survival(<2 months) after WBRT , also the survival for groups with poor prognostic score based on of RPA OR DS GPA is still heterogonous. I propose looking into another group of predictive models for detection of brain metastases in cancer patients, in particular for the asymptomatic group, and image the brain mainly with MRI to detect limited metastasis which could be treated with focal treatment to improve the survival.

\section{References}

1. Nathoo N, Toms SA, Barnett GH (2004) Metastases to the brain: Current management perspectives. Expert Rev Neurother 4(4): 633-640.

2. Fidler IJ (2015) The biology of brain metastasis: Challenges for therapy. Cancer 21(4): 284-293.

3. Conrad CA (2001) Chemotherapy for metastatic tumors to the central nervous system. Curr Oncol Rep 3(6): 490-494.

4. Posner JB (1996) Brain metastases: 1995. A brief review. J Neurooncol 27(3): 287-293.

5. Nayak L, Lee EQ Wen PY (2014) Epidemiology of brain metastases. Curr Oncol Rep 14(1): 48-54.

6. Akhavan A, Binesh F, Heidari S (2014) Survival of brain metastatic patients in Yazd, Iran. Asian Pac J Cancer Prev 15(8): 3571-3574.

7. Villa S, Weber DC, Moretones C, Manes A, Combescure C, et al. (2011) Validation of the new graded prognostic assessment scale for brain metastases: A multicenter prospective study. Radiat Oncol 6: 23-31.

8. Saha A, Ghosh SK, Roy C, Choudhury KB, Chakrabarty B, et al. (2013) Demographic and clinical profile of patients with brain metastases: A retrospective study. Asian J Neurosurg 8(3):157-161.

9. Jena A, Taneja S, Talwar V, Sharma JB (2008) Magnetic resonance (MR) patterns of brain metastasis in lung cancer patients: correlation of imaging findings with symptom. J Thorac Oncol 3(2): 140-144.

10. Cairncross JG, Kim JH, Posner JB (1980) Radiation therapy for brain metastases. Ann Neurol 7(6): 529-541.
11. Lynam LM, Lyons MK, Drazkowski JF, Sirven JI, Noe KH, et al. (2007) Frequency of seizures in patients with newly diagnosed brain tumors: a retrospective review. Clin Neurol Neurosurg 109(7): 634-638.

12. Sheikhbahaei S, Mena E, Yanamadala A, Reddy S, Solnes LB, et al. (2017) The value of FDG PET/CT in treatment response assessment, follow-up, and surveillance of lung cancer. AJR 208(2): 420-433.

13. Hjorthaug K, Hojbjerg J, Knap MM, Tietze A, Haraldsen A, et al. (2015) Accuracy of 18F-FDG PET/CT in triaging lunch cancer patients with suspected brain metastases for MRI. Nucl Med Commun 36(11): 10841090.

14. Schellinger PD, Meinck HM, Thron A (1999) Diagnostic accuracy of MRI compared to CCT in patients with brain metastases. J Neurooncol 44(3): 275-281.

15. Gaspar L, Scott C, Rotman M, Asbell S, Phillips T, et al. (1997) Recursive partitioning analysis (RPA) of prognostic factors in three radiation therapy oncology group (RTOG) brain metastases trials. Int J Radiat Oncol Biol Phys 37(4): 745-751.

16. Ekici K, Temelli O, Dikilitas M, HalilDursun I, Bozdag Kaplan N, et al. (2016) Survival and prognostic factors in patients with brain metastasis: Single center experience. J Buon 21(4): 958-963.

17. Frazier JL, Batra S, Kapor S, Vellimana A, Gandhi R, et al. (2010) Stereotactic radiosurgery in the management of brain metastases: An institutional retrospective analysis of survival. Int J Radiat Oncol Biol Phys 76(5): 1486-1492.

18. Golden DW, Lamborn KR, McDermott MW, Kunwar S, Wara WM, et al. (2008) Prognostic factors and grading systems for overall survival in patients treated with radiosurgery for brain metastases: Variation by primary site. J Neurosurg 109(Suppl): 77-86.

19. Lagerwaard FJ, Levendag PC (2001) Prognostic factors in patients with brain metastases. Forum (Genova)11(1): 27-46.

20. Hazuka MB, Burleson WD, Stroud DN, Leonard CE, Lillehei KO, et al. (1993) Multiple brain metastases are associated with poor survival in patients treated with surgery and radiotherapy. J Clin Oncol 11(2): 369373.

21. Gaspar L, Scott C, Rotman M, Asbell S, Phillips T, et al. (1997) Recursive partitioning analysis (RPA) of prognostic factors in three Radiation Therapy Oncology Group (RTOG) brain metastases trials. Int J Radiat Oncol 37(4): 745-751.

22. Sperduto W, Kased N, Roberge Z, Xu Z, Shanley R, et al. (2011) Summary report on the graded prognostic assessment: an accurate and facile diagnosis-specific tool to estimate survival for patients with brain metastases. J Clin Oncol 30(4): 419-425.

23. Sperduto PW, Chao ST, Sneed PK, Luo X, Suh J, et al. (2010) Diagnosisspecific prognostic factors, indexes, and treatment outcomes for patients with newly diagnosed brain metastases: a multi-institutional analysis of 4259 patients. Int J Radiat Oncol Biol Phys 77(3): 655-661.

24. Nieder C, Spanne O, Mehta MP, Grosu AL, Geinitz H (2011) Presentation, patterns of care, and survival in patients with brain metastases: what has changed in the last 20 years? Cancer 117(11): 2505-2512.

25. Fabi A, Felici A, Metro G, Mirri A, Bria E, et al. (2011) Brain metastases from solid tumors: Disease outcome according to type of treatment and therapeutic resources of the treating center. J Exp Clin Cancer Res 30:10.

26. Sperduto PW, Berkey B, Gaspar LE, Mehta M, Curran W (2008) A new prognostic index and comparison to three other indices for patients with brain metastases: an analysis of 1,960 patients in the RTOG database. Int J Radiat Oncol Biol Phys 70(2): 510-514. 